\title{
Identification of Painting Layers of Sennefer Tomb by Ion Beam Analysis
}

\author{
S. ABd El AAL* \\ Conservation Department, Faculty of Archaeology, Fayoum University, P.O. Box 63511, Egypt
}

\begin{abstract}
Egypt has many pharaonic tombs for kings, queens and noblemen. The Sennefer tomb, one of the most important nobleman tombs, is located in the southern hillside of Sheikh Abd El-Qurna — west side of Luxor. It is dated back to 1439-1413 B.C. (18th Dynasty) and is usually referred as the Tomb of Vines, due to the large part of the ceiling of the burial chamber. The vine tomb was carved inside a mountain, its walls are covered with plaster and were painted using the tempera technique (pigments mixed with organic binding medium). The analysis was performed by using particle-induced X-ray emission, microbeam particle-induced X-ray emission and optical microscope for the six samples from the Vine tomb such as white, black, red, yellow, blue and green pigments and for the ground layers of the tomb in order to identify the composition of plaster layers and pigments. The data about the nature of these materials are indispensable for conservation and cleaning.
\end{abstract}

PACS: 78.70.En, 07.60.Pb

\section{Introduction}

Sennefer's career appears to have developed during the reign of Amenhotep II (about 1439-1413 B.C., during Egypt's 18th Dynasty), when he became mayor of Thebes, which during his time was the most important Egyptian city. Egypt was very prosperous, and because of the importance of its temples, particularly that of Amun to whom Pharaoh owed his brilliant victories, considerable revenue flowed into this particular region. His tomb, known by 19th century travelers as the "Tomb of the Vineyards" because of the decorative theme of its ceiling, attests to the fact that he received a fair share of these proceeds. Sennefer's titles, shown on the walls of his tomb, are varied, but the main one attached to his name is that of Mayor of Thebes.

The aim of the study was to provide typical data for archaeological identification of pigments and ground layers like their chronology or identification of materials, whether they are domestic or imported. Moreover, such a study is important for conservation of paintings. For a long time wall paintings were subjected to many deterioration factors both natural and human made, which led to their degradation by discoloration and mechanical decomposition $[1,2]$. Many misidentifications of materials were made by archaeologists before the introduction of accurate instrumental analytical techniques. Hence, before starting any conservation or restoration activity, the precise knowledge of the used pigments as well as their deposition sequence is indispensable. On this basis one

* e-mail: smm00@fayoum.edu.eg can select the suitable methods and materials for conservation and primarily the judicious choice of chemical treatment for cleaning. It is worth pointing out that selection of a pigment of the same hue but different from the original one can lead to the chemical reaction between them with final disastrous effect. Finally, identification of pigments is a very reliable method for testing artwork authenticity.

A typical structure of a wall painting consists of four layers of different composition and structure. The first layer is the support, which simply is the wall of a tomb; the second one is a coarse ground layer usually being the mixture of gypsum, lime and quartz. The third grounding layer consisted of a fine grain plaster made of gypsum or lime and the last one was the paint. Paint is a mixture of fine grain natural or synthetic pigments with organic binder. The last one enables the smooth distribution of pigments on the surface and assures adhesion of the paint to the substrate. Typical binders were Arabic gum, animal glue, or egg yolk $[2,3]$.

Continuous degradation of wall paintings leads also to its mechanical disintegration: many studied samples exhibit discontinuous paint layer because at different places paint patches flaked off exposing the underlying grounding layer. This effect, if not taken into account, can lead to erroneous interpretation of experimental results.

\section{Objects studied}

We have analyzed pigments and ground layers used for wall paintings from the Sennefer tomb which is located in the southern hillside of Sheikh Abd El-Qurna - west side of Luxor, Egypt. It is dated back to 1439-1413 B.C. (18th Dynasty). 
All analyzed specimens were loose pieces of wall paintings collected on the spot in different objects. They consisted of thick painted plaster. Their face area was usually less than $1 \mathrm{~cm}^{2}$ and they were 1 to $10 \mathrm{~mm}$ thick. The samples were thinned by polishing up to 1-2 mm thickness and cleaned with ethanol. Because of their great brittleness care has to be taken during the preparation and handling.

\section{Experimental methods}

\subsection{Optical microscopy}

Axiotron Zeiss optical microscope at the Institute of Electronic Materials Technology (ITME) in Warsaw and Forschungszentrum Dresden (FZD) was used to visualize the surface of painting. In order to visualize the paint cross-section some samples were prepared in a special manner. Samples were thinned to about $1 \mathrm{~mm}$ and subsequently immersed in the fluid Meliodent resin. Meliodent can be obtained by mixing two components: the first one is powder polymethyl methacrylate and the other one is liquid mixture of dimethacrylate and methyl methacrylate. After being mixed in correct proportions it solidifies at room temperature (RT). After solidification of resin samples were fine grain polished to obtain flat surface exposing the cross-section of paint. Cross-section observations provided information about the number of painted layers, their sequence and thickness as well as the size of pigment grains.

\subsection{PIXE analysis}

Particle-induced X-ray emission (PIXE) is one of the most sensitive micro analytical methods [4]. It is non-destructive and is currently used for multi-elemental analysis both in vacuum and air. The "in vacuum" mode is advantageous for detection of low atomic number elements [5].

The broad beam PIXE analysis with $1.0 \mathrm{MeV}$ protons was performed at the Soltan Institute of Nuclear Studies (SINS), Warsaw using the Lech Van de Graaff accelerator. Protons prior to entering the target chamber were collimated by two graphite collimators with a diameter of $1 \mathrm{~mm}$. The beam current was between $5 \mathrm{nA}$ and $20 \mathrm{nA}$, the total charge during the irradiation ranged from $0.1 \mathrm{mC}$ to $0.5 \mathrm{mC}$.

The X-rays generated in the samples were measured by the $7 \mathrm{~mm}^{2}$ AMBEK Inc. (Belford, USA) Si (Li) detector with the $25 \mu \mathrm{m}$ Be window, placed at $90^{\circ}$ or $180^{\circ}$ to the beam direction outside the experimental chamber. Energy resolution (FWHM) of the X-ray spectrometer was $180-200 \mathrm{eV}$ at $6.4 \mathrm{keV}$. Energy calibration of X-ray spectrometer was checked during experimental runs by ${ }^{241} \mathrm{Am}$ standard radioactive source. The analyzed samples with dimensions from $2 \times 3 \mathrm{~mm}^{2}$ up to $10 \times 10 \mathrm{~mm}^{2}$ were mounted on the 8 position target holder perpendicular to the beam direction. Rotation of the target holder by $180^{\circ}$ enables sample analysis from both sides i.e. front and back. This was especially important for the samples with a discontinuous paint layer: the final evaluation of data was performed for the spectrum resulting from subtraction of that taken for the front side (face) from the other one for the support (back). This procedure made it possible to perform qualitative analysis even of partially flaked off paint layer.

\section{3. $\mu-P I X E$ analysis}

The scanning microbeam-PIXE analysis allows identification of elements by taking high resolution elemental maps of the sample by scanning an area of $2 \mathrm{~mm}$ square with a narrow beam focused to $1 \mu \mathrm{m}[6,7]$. A proton beam of $3.05 \mathrm{MeV}$ from the $3 \mathrm{MV}$ Tandetron accelerator at FZD was used for $\mu$-PIXE analysis. An Ortec $\mathrm{Si}(\mathrm{Li})$ detector was located outside the chamber behind a $125 \mu \mathrm{m}$ thick Be windows allowing detection of characteristic X-rays for elements heavier than Na. Since pigment grain sizes are usually of $20-100 \mu \mathrm{m}$ and the range of $3 \mathrm{MeV}$ protons in a typical pigment compound is above $50 \mu \mathrm{m}$ even $\mu$-PIXE did not allow analysis of a single grain composition without any interference of the substrate and/or neighboring pigments or binder. The analysis was performed in three steps: first the region of interest was selected in situ with an optical microscope equipped with a CCD camera, next the beam of $5 \mu \mathrm{m} \times 5 \mu \mathrm{m}$ size was scanned across the selected area, usually $105 \times 105 \mu \mathrm{m}^{2}$ to get an elemental map, and finally in the region of maximum abundance of elements typical for a given pigment the PIXE spectrum was measured with good statistics. Although PIXE is in principle a quantitative technique, quantifying the spectra, especially for these thick layers that are non-uniform both laterally and in depth, is a tremendous challenge. However, full quantification is unnecessary in this case since the simple recognition of key-elements is sufficient for pigment identification.

Moreover, the windows in front of the detector and in the vacuum chamber in our experimental setup were so thick that transmission of X-rays characteristic of Si or S (about $2 \mathrm{keV}$ ) was approximately $80 \%$ and $90 \%$, respectively. Taking into account the absorption in the sample itself, one can estimate that for the elements lighter than Ca characteristic X-rays can only be detected if produced in the surface layer of less than $1 \mu \mathrm{m}$ thickness. Since for pigment identification the recognition of key elements is typically sufficient, no attempt to quantify PIXE analysis has been undertaken.

\section{Results and discussion}

From the Sennefer tomb only seven pigments samples with its ground painting were selected to describe the analytical procedure and highlight the virtues of ion beam analysis of ancient pigments.

\subsection{White pigment}

White pigment samples were collected from the wall of the Vine Tomb. White pigment was frequently used in 
ancient Egypt. The most common were gypsum, calcite, and huntite [8]. As can be seen in Fig. 1, PIXE spectra revealed that $\mathrm{Si}, \mathrm{S}, \mathrm{Cl}$, $\mathrm{Ti}$ and $\mathrm{Ca}$ are present in the surface layer. Since Ca is main component of gypsum, the answer to the question about the white pigment nature seems to be straightforward.

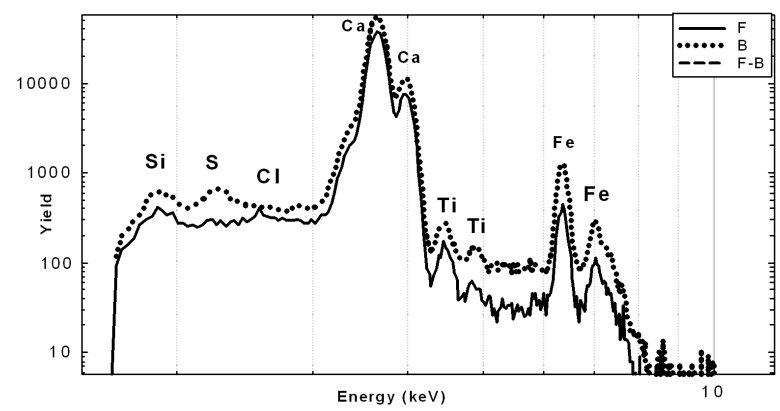

Fig. 1. PIXE spectra obtained for the white pigment sample. Two spectra were taken for each sample: for the face and back sides. After subtraction of the face spectrum from the back one, the paint composition was determined.

\subsection{Black pigment}

Black pigment samples were collected from area of head from the wall of the Vine Tomb. Black pigment was frequently used in ancient Egypt. The most common were soot, carbon black (lamb black), charcoal, bone black, and pyrolusite [8]. As can be seen in Fig. 2 PIXE spectra revealed that $\mathrm{Si}, \mathrm{S}, \mathrm{Cl}, \mathrm{Ti}$ and $\mathrm{Ca}$ are present in the surface layer, since carbon as a light element cannot appear in PIXE spectra.

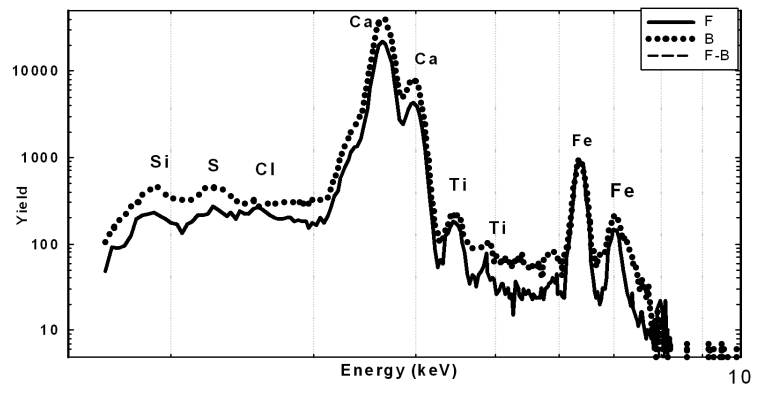

Fig. 2. As in Fig. 1, but for the black pigment sample.

Optical micrographs showed that the paint layer is strongly degraded and discontinuous, however, it was originally of the uniformly black color. The observation limit is of few of black grains of carbon.

\subsection{Red pigment}

Red pigment was collected from the red painted area from the tomb. The spectra of broad beam PIXE for this sample are shown in Fig. 3. The spectrum taken for the sample face reveals the presence of the elements like $\mathrm{Si}$, $\mathrm{S}, \mathrm{Ca}, \mathrm{Ti}$ and Fe. After subtraction of the spectrum for the backside only $\mathrm{Si}, \mathrm{S}, \mathrm{Ca}$ and Fe were identified as the elements present in the paint.

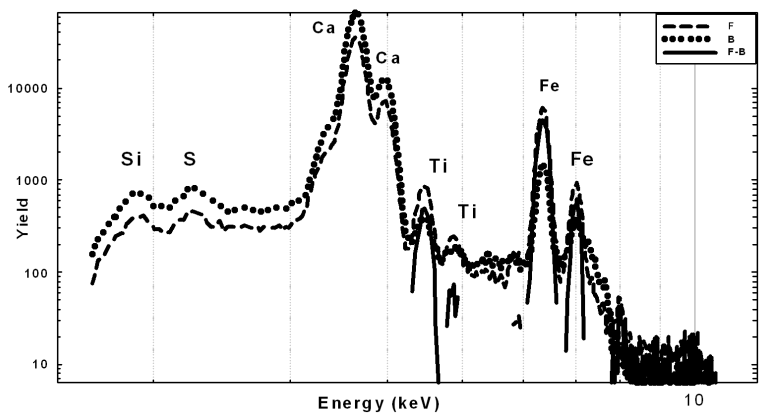

Fig. 3. As in Fig. 1, but for the red pigment sample.

Optical micrographs gave important clues for the solution of this puzzle. The paint layer is strongly degraded and discontinuous, however, it was originally of the uniformly red colour. Under large magnification a few darker inclusions in the upper paint layer of about $40 \mu \mathrm{m}$ diameter were visualized. In the cross-sectional micrographs only one paint layer can be distinguished. This red layer is rather thin being $10 \mu \mathrm{m}$ thick with very small pigment grains, below the observation limit of a few black grains of carbon. Based on the archaeological knowledge of the ancient Egyptian pigments, the following conclusions can be drawn from our analysis:

- since the paint layer is discontinuous, signals from $\mathrm{Si}$ and $\mathrm{Ca}$ are apparently coming from the plaster substrate,

- the presence of intense Fe signal can be attributed to deep red paint layer whose pigment was most probably the fine powdered mineral hematite, $\mathrm{Fe}_{2} \mathrm{O}_{3}$ - the so-called red ochre was very often used pigment, commonly present in the Egyptian soil,

- maybe some black carbon was added to red pigments to obtain a dark red pigment.

\subsection{Yellow pigment}

Yellow pigment was collected from the yellow painted parts from the tomb. The spectra of broad beam PIXE for this sample are shown in Fig. 4. The spectrum taken for the sample face reveals the presence of the elements like $\mathrm{Si}, \mathrm{S}, \mathrm{Ca}, \mathrm{Ti}$, and Fe. After subtraction of the spectrum for the backside only $\mathrm{Si}, \mathrm{S}, \mathrm{Ca}$ and Fe were identified as the elements present in the paint.

Optical micrographs showed that the paint layer is strongly degraded and discontinuous, however, it was originally of the uniformly yellow color. With large magnification, a few darker inclusions in the upper paint layer of about $40 \mu \mathrm{m}$ diameter were visualized. In the cross-sectional micrographs only one paint layer can be distinguished. This yellow layer is rather thin $(30 \mu \mathrm{m}$ thick) with very small pigment grains, since the paint layer is discontinuous. Signals from $\mathrm{Si}$ and $\mathrm{Ca}$ are apparently coming from the plaster substrate. The presence 


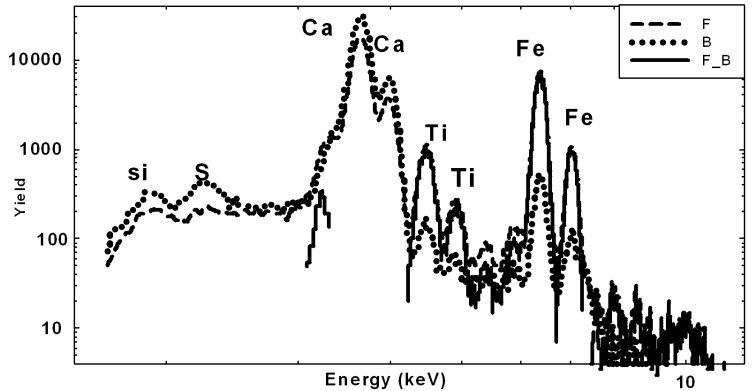

Fig. 4. As in Fig. 1, but for the yellow pigment sample.

of intense Fe signal can be attributed to the deep yellow paint layer whose pigment was most probably fine powdered mineral, yellow ochre mineral $\alpha$-FeOOH, so-called goethite was very common used pigment.

\subsection{Blue pigment}

The blue pigment samples were collected from the ceiling of the Vine Tomb. Blue pigment was frequently used in ancient Egypt. The most common were azurite $2 \mathrm{CuCO}_{3} \cdot \mathrm{Cu}(\mathrm{OH})_{2}$ - a natural pigment and the synthetic pigment cuprorivaite - $\mathrm{CaCuSi}_{4} \mathrm{O}_{10}$ called Egyptian Blue [9]. Egyptian Blue has been known since 2500 B.C. and is the oldest known synthetic pigment. It was prepared from natural materials and fine metal scraps by firing the mixtures at temperatures of about $800^{\circ} \mathrm{C}$. As can be seen in Fig. 5 the PIXE spectra revealed that $\mathrm{Si}, \mathrm{Ca}, \mathrm{Fe}, \mathrm{Cu}$ are present in the surface layer which was confirmed by the $\mu$-PIXE analysis. Since $\mathrm{Cu}$, $\mathrm{Ca}$ and $\mathrm{Si}$ are main components of Egyptian Blue, the answer to the question about the blue pigment nature seems to be straightforward. However, the strong Fe signal in all spectra was annoying. Actually, one cannot expect Fe containing compounds in this configuration.

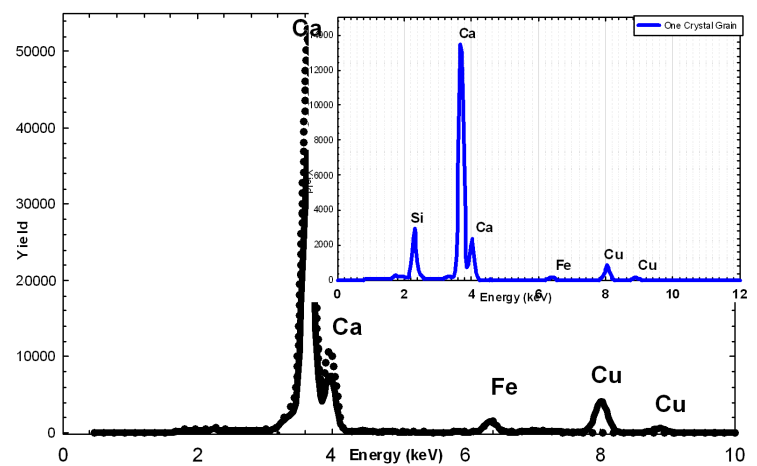

Fig. 5. As in Fig. 1, but for the blue pigment sample. $\mu$-PIXE spectrum obtained for one selected pigment grain shown in the inset.

Optical microscopy helped resolve this puzzle. Dark blue Egyptian Blue grains of the size 10-40 $\mu \mathrm{m}$ are mixed with light blue grains of more or less the same size. It is known that the temperature regime of Egyptian Blue synthesis is critical. If the temperature raises above $1000^{\circ} \mathrm{C}$ instead of Egyptian Blue wollastonite $(\mathrm{CaCu})$ $\mathrm{SiO}_{3}$ of light blue-greenish color will be synthesized. As a consequence the chromatic hue of prepared pigment was not dark enough. To save the precious pigment the ancient masters blended it with very fine grained hematite $\mathrm{Fe}_{2} \mathrm{O}_{3}$ obtaining as expected deep dark blue hue. Apparently very fine hematite grains are below the optical microscope resolution but hematite was detected as the Fe signal by PIXE.

\subsection{Green pigment}

Green pigment was collected from the green painted area (grapes) from the tomb, from non-important places. The studied specimen is a piece from the wall. The spectra of broad beam PIXE for this sample are shown in Fig. 6. The spectrum taken for the sample face reveals the presence of the elements like $\mathrm{Si}, \mathrm{S}, \mathrm{Ca}$, Ti and Fe; after subtraction of the spectrum for the backside only $\mathrm{Ti}$ and Fe were identified as the elements present in the paint.

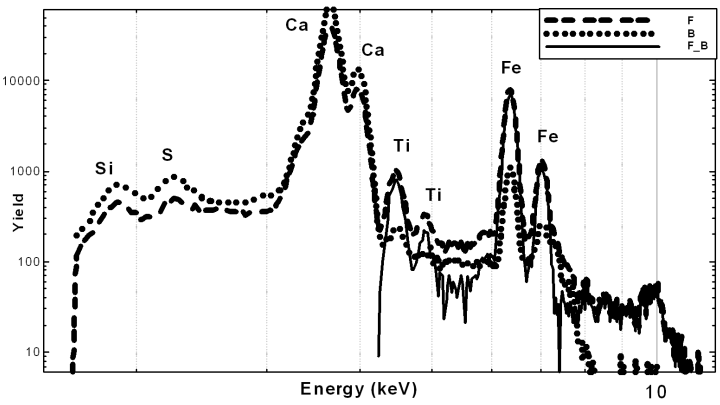

Fig. 6. As in Fig. 1, but for the green pigment sample.

The optical micrographs showed that the paint layer is strongly degraded and discontinuous, however, it was originally of the uniformly green colour. With large magnification a few darker inclusions in the upper paint layer of about $40 \mu \mathrm{m}$ diameter were visualized. In the cross-sectional micrographs only one paint layer can be distinguished. This green layer is rather thin (30 $\mu \mathrm{m}$ thick) with very small pigment grains. Based on the archaeological knowledge of the ancient Egyptian pigments, the following conclusions can be drawn from our analysis: since the paint layer is discontinuous, signals from $\mathrm{Si}$ and $\mathrm{Ca}$ are apparently coming from the plaster substrate.

The presence of intense Fe signal can be attributed to the deep green paint layer whose pigment was most probably a fine powdered mineral, complex alumina silicate minerals $\mathrm{K}[(\mathrm{Al}, \mathrm{Fe}),(\mathrm{Fe}, \mathrm{Mg})]\left(\mathrm{AlSi}_{3}, \mathrm{Si}_{4}\right) \mathrm{O}_{10}(\mathrm{OH})_{2}-$ this so-called green earth was a very rarely used pigment. Maybe some black carbon was added to green pigments to obtain a dark green one. 


\section{Conclusions}

The principal aim of this research project was to identify the composition of pigments and ground layers used in the ancient Tomb of Vines. PIXE, $\mu$-PIXE and optical microscopy were successfully applied for the purpose. Our observations can be summarized as follows:

- the white pigment is $\mathrm{CaSO}_{4} \cdot 2 \mathrm{H}_{2} \mathrm{O}$, as gypsum,

- PIXE cannot detect carbon element as the black pigment in the Sennefer tomb but optical micrograph can easily notice that carbon is used as a black pigment,

- red pigment was identified as hematite $\left(\mathrm{Fe}_{2} \mathrm{O}_{3}\right)$,

- yellow pigment was identified as goethite $(\alpha \mathrm{FeOOH})$,

- blue pigment was composed of the mixture of Egyptian Blue blended with hematite.

Besides pigment identification, we are also able to draw some conclusions about the painting technique of ancient masters. They used various methods to change the chromatic hue of principal pigment, like adjusting grain size by appropriate grinding, blending with other pigments, or creating multilayer structures.

The analysis of these selected samples clearly demonstrates usefulness of the ion beam techniques for this kind of analysis. Although the obtained results have not always led to unambiguous conclusions, many important clues were provided by microscopic observations.

Concluding, it should be pointed out that such a study makes only sense if it is embedded in the immense treasure of archaeological knowledge acquired in the last two centuries.

\section{Acknowledgments}

Sincere thanks are due to Prof. A. Turos and A. Stonert from the Institute of Electronic Materials Technol- ogy, Poland, to Ms. M. Możdżonek (ITME) and Dr. B. Schmidt (FZD) for their help with optical microscopy. $\mu$-PIXE analyses have been carried out at the AIM of the Institute of Ion Beam Physics and Materials Research of the Forschungszentrum Dresden-Rossendorf.

\section{References}

[1] P.T. Nicholson, I. Shaw, Ancient Egyptian Materials and Technology, Cambridge University Press, Cambridge 2000 .

[2] A. Lucas, Ancient Egyptian Materials and Industries, Kessinger Publishing, London 2003.

[3] U. Lindborg, Conservation of Mural Paintings, National Heritage Board, Stockholm 2001.

[4] S.A. Johansson, J.L. Campbell, K.G. Malmqvist, Particle-Induced X-ray Emission Spectrometry (PIXE), Wiley-Interscience, New York 1995.

[5] M. Uda, S. Sassa, S. Yoshimura, J. Kondo, M. Nakamura, Y. Ban, H. Adachi, Nucl. Instrum. Methods Phys. Res. B 161-163, 758 (2000).

[6] M. Uda, Nucl. Instrum. Methods Phys. Res. B 226, 75 (2004).

[7] C. Neelmeijer, M. Mader, Nucl. Instrum. Methods Phys. Res. B 189, 293 (2002).

[8] A. El Goresy, in: Proc. First Thera Int. Symp., Ed. P.M. Nomikos, Thera, Greece 1997, p. 49.

[9] P. Bianchetti, F. Talarico, M.G. Vigliano, M.F. Ali, J. Cult. Herit. 1, 179 (2000). 